\title{
ADTF SPOKE CAVITY CRYOMODULE CONCEPT
}

\author{
J.P. Kelley, P.L. Roybal, R.P. LaFave, R.C. Gentzlinger, J.A. Waynert, D.L. \\ Schrage, E. Schmierer, F. Krawczyk, R.W. Garnett, T. Tajima \\ Los Alamos National Laboratory \\ Los Alamos, NM, 87545, USA
}

\begin{abstract}
The Accelerator Driven Test Facility (ADTF) is being developed as a reactor concepts test bed for transmutation of nuclear waste. A $13.3 \mathrm{~mA}$ continuous-wave $(\mathrm{CW})$ proton beam will be accelerated to $600 \mathrm{MeV}$ and impinged on a spallation target. The subsequent neutron shower is used to create a nuclear reaction within a subcritical assembly of waste material that reduces the waste half-life from the order of $10^{5}$ years to $10^{2}$ years. Additionally, significant energy is produced that can be used to generate electrical power.

The ADTF proton accelerator consists of room-temperature (RT) structures that accelerate the beam to $6.7-\mathrm{MeV}$ and superconducting (SC) elements that boost the beam's energy to $600-\mathrm{MeV}$. Traditional SC elliptical cavities experience structural difficulties at low energies due to their geometry. Therefore, stiff-structured SC spoke cavities have been adopted for the energy range between 6.7 and $109 \mathrm{MeV}$. Elliptical cavities are used at the higher energies. This paper describes a multi-spoke-cavity cryomodule concept for ADTF.
\end{abstract}

\section{INTRODUCTION}

The Accelerator Driven Test Facility (ADTF) is being developed as a reactor concepts test bed for transmutation of nuclear waste. A $13.3 \mathrm{~mA} \mathrm{CW}$ proton beam will be accelerated to $600 \mathrm{MeV}$ and impinged on a spallation target. Spallation neutrons are used to create a nuclear reaction within a subcritical assembly of waste material. The reaction produces significant usable energy and reaction products with greatly reduced half-lives.

The $600-\mathrm{MeV}$ ADTF proton accelerator consists of a $6.7-\mathrm{MeV}$ RT radio frequency quadrupole accelerating structure, and a 6.7 to $600-\mathrm{MeV}$ superconducting (SC) accelerator. Geometry related structural difficulties limit the use of traditional elliptical SC cavities at low energies. Therefore, stiff-structured, $350 \mathrm{MHz}$ SC spoke cavities [1] have been adopted for the energy range between 6.7 and $109 \mathrm{MeV}$ [2], the Low Energy Linac (LEL). Elliptical cavities are used at the higher energies.

The beam dynamics design [2] dictates that cavities of three $\beta$ types be used in the LEL: $\beta=0.175$ two-gap cavities [3], and $\beta=0.2$ and $\beta=0.34$ three-gap cavities, where $\beta$ is the ratio of particle speed to the speed of light. 

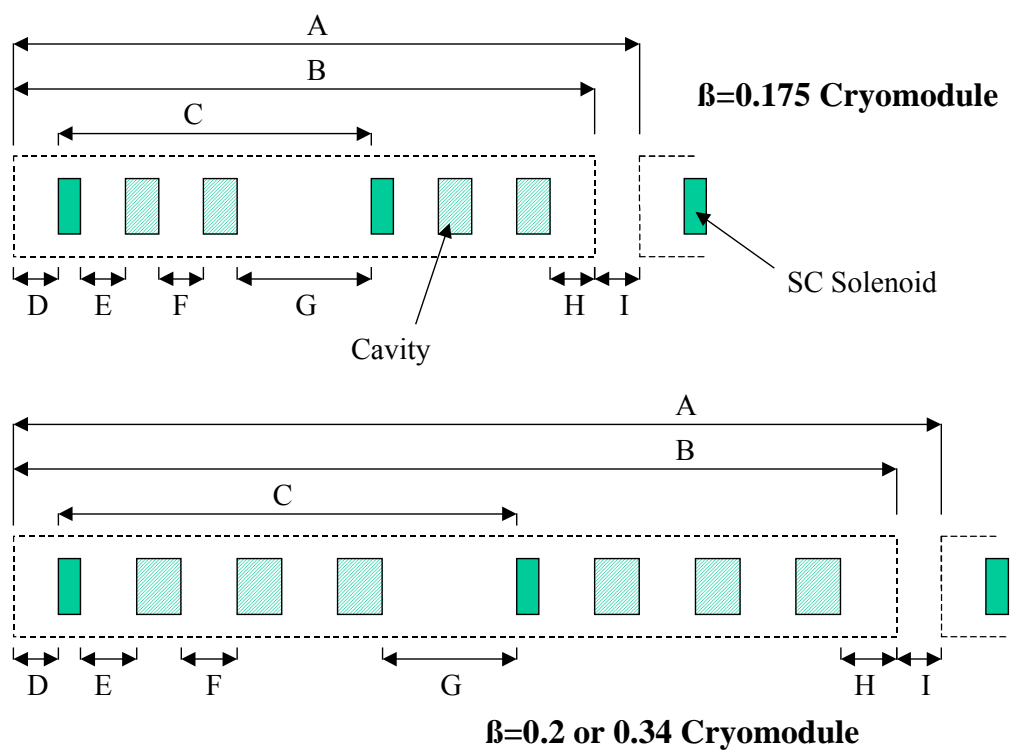

FIGURE 1. Layout schematic of the ADTF LEL Cryomodules. Letters refer to Table 1.

Fig. 1 is a schematic layout of the cryomodules. A $\beta=0.175$ lattice element consists of a solenoid magnet and two cavities. For the higher $\beta$ structures, the lattice consists of a solenoid magnet and three cavities. Cryomodule lengths (Table 1) were dictated by:

(1) The need to reduce LEL length and total system costs by minimizing distances between elements. This led to inclusion of the solenoids as SC elements in the cryomodule.

(2) The need for periodic warm spaces for beam diagnostics,

(3) The desire to maximize cryomodule lengths to minimize the total number of warm to cold transitions, reducing heat loads and distribution system complexity, and

(4) The need to fit the module elements into the existing cleanroom [4].

This paper describes a cryomodule concept for the multi-spoke ADTF $\beta=0.34$ cavities. Efforts were focused on this unit since it was felt that its greater overall length coupled with the potential interface difficulties with the center cavities in the three cavity arrays (tuner, coupler, etc. - due to position) would make it the most challenging of the three units.

\section{CONCEPTUAL DESIGN DEVELOPMENT}

The basic requirements for the LEL cryomodules are given in Table 2. During cryomodule design development, the following basic guidelines were used:

(1) Where possible, adopt concepts and components from previous programs.

TABLE 1. Dimensions of the three LEL cryomodules. Letters refer to Fig. 1.

\begin{tabular}{lcccc}
\hline & & $\boldsymbol{\beta}=\mathbf{0 . 1 7 5}$ & $\boldsymbol{\beta}=\mathbf{0 . 2}$ & $\boldsymbol{\beta = 0 . 3 4}$ \\
\hline Cryomodule Period & $\mathrm{A}$ & $4.53 \mathrm{~m}$ & $6.10 \mathrm{~m}$ & $6.92 \mathrm{~m}$ \\
Cryomodule Length & $\mathrm{B}$ & $4.23 \mathrm{~m}$ & $5.80 \mathrm{~m}$ & $6.62 \mathrm{~m}$ \\
Focusing Period & $\mathrm{C}$ & $2.26 \mathrm{~m}$ & $3.05 \mathrm{~m}$ & $3.46 \mathrm{~m}$ \\
Warm to Cold Transition (1) & $\mathrm{D}$ & $0.39 \mathrm{~m}$ & $0.39 \mathrm{~m}$ & $0.39 \mathrm{~m}$ \\
Magnet to Cavity Drift & $\mathrm{E}$ & $0.3 \mathrm{~m}$ & $0.3 \mathrm{~m}$ & $0.3 \mathrm{~m}$ \\
Cavity to Cavity Drift & $\mathrm{F}$ & $0.3 \mathrm{~m}$ & $0.3 \mathrm{~m}$ & $0.3 \mathrm{~m}$ \\
Cavity to Magnet Drift & $\mathrm{G}$ & $1.11 \mathrm{~m}$ & $1.11 \mathrm{~m}$ & $1.11 \mathrm{~m}$ \\
Warm to Cold Transition (2) & $\mathrm{H}$ & $0.42 \mathrm{~m}$ & $0.42 \mathrm{~m}$ & $0.42 \mathrm{~m}$ \\
Cryomodule to Cryomodule Drift & $\mathrm{I}$ & $0.3 \mathrm{~m}$ & $0.3 \mathrm{~m}$ & $0.3 \mathrm{~m}$ \\
Magnet Physical Length & & $0.15 \mathrm{~m}$ & $0.15 \mathrm{~m}$ & $0.15 \mathrm{~m}$ \\
Cavity Physical Length & & $0.20 \mathrm{~m}$ & $0.30 \mathrm{~m}$ & $0.43 \mathrm{~m}$ \\
\hline
\end{tabular}


TABLE 2. Cryomodule parameters.

\begin{tabular}{lccc}
\hline & $\boldsymbol{\beta}=\mathbf{0 . 1 7 5}$ & $\boldsymbol{\beta}=\mathbf{0 . 2}$ & $\boldsymbol{\beta}=\mathbf{0 . 3 4}$ \\
\hline $\mathrm{Q}_{\mathrm{o}}$ & $1.72 \mathrm{E} 9$ & $1.92 \mathrm{E} 9$ & $2.50 \mathrm{E} 9$ \\
$\mathrm{E}_{\text {acc }}$ & $5 \mathrm{MV} / \mathrm{m}$ & $5 \mathrm{MV} / \mathrm{m}$ & $5 \mathrm{MV} / \mathrm{m}$ \\
Frequency & $350 \mathrm{MHz}$ & $350 \mathrm{MHz}$ & $350 \mathrm{MHz}$ \\
Coupled Power @ 13.3mA(100 mA) & $4.7(35.3) \mathrm{kW}$ & $10.35(77.8) \mathrm{kW}$ & $18.6(139.8) \mathrm{kW}$ \\
Cavity Operating Temperature & $4.5 \mathrm{~K}$ & $4.5 \mathrm{~K}$ & $4.5 \mathrm{~K}$ \\
Cavity External Magnetic Field (Goal) & $5 \mathrm{milli-Gauss}$ & $5 \mathrm{milli}-\mathrm{Gauss}$ & $5 \mathrm{milli}-\mathrm{Gauss}$ \\
Cavity Mechanical Resonance & $>200 \mathrm{~Hz}$ & $>200 \mathrm{~Hz}$ & $>200 \mathrm{~Hz}$ \\
Tuning Stiffness & $26 \mathrm{kHz} / \mathrm{mil}$ & To Be Determined & To Be Determined \\
& $0.31 \mathrm{kHz} / \mathrm{lb}$. & & \\
Cavity Detuning Rate in $<300 \mathrm{msec}$ & $67 \mathrm{kHz} / \mathrm{sec}$ & To Be Determined & To Be Determined \\
& $67 \mathrm{micron} / \mathrm{sec}$ & & \\
Shield Operating Temperature & $40-55 \mathrm{~K}$ & $40-55 \mathrm{~K}$ & $40-55 \mathrm{~K}$ \\
Solenoid Field & $1.8-2.32 \mathrm{~T}$ & $2.5-4.0 \mathrm{~T}$ & $4.0-5.4 \mathrm{~T}$ \\
Current & $20 \mathrm{~A}$ & $20 \mathrm{~A}$ & $20 \mathrm{~A}$ \\
Lead Type & Conduction Cooled & Conduction Cooled & Conduction Cooled \\
\hline
\end{tabular}

(2) To minimize cleanroom time and simplify assembly, insert helium vessel assemblies axially into the vacuum vessel. Minimizing radial penetrations is a corollary.

(3) Adopt design similarity between the three module types. With the exception of length, parts are identical.

(4) Since ADTF has it roots in the Accelerator Production of Tritium Program (APT) [5],

(a) it must be upgradable to $100 \mathrm{~mA}$ operations for tritium production.

(b) the ADTF cryomodule must fit into the APT tunnel design.

Note that since the completion of this work, requirement (4)(b) has been eliminated.

The drive to minimize length led to the placement of the principle cryogenic and other penetrations in a Tee shaped section at the center of the module in the gap made available by the beam dynamics design (Section G in Fig. 1).

Fig. 2(a) shows a $\beta=0.175$ two-gap spoke cavity. Cavities must be tuned individually. Tuning requirements dictated that both end walls of a spoke cavity be flexed, resulting in a tuner assembly that straddles the cavity. If an individual cavity and tuner were housed in a helium vessel, the helium vessel size would increase, and require multiple penetrations. To minimize spacing between cavities, essentially flat helium vessel heads would be necessary, requiring thicker material or elaborate stiffeners. If multiple cavities with tuners were housed in a single vessel, the length would dictate elaborate penetrations to accommodate thermal contractions. Therefore, it was decided to house each cavity in an individual titanium helium vessel (Fig. 2(b)) with the tuner outside of the vessel (Fig. 3). A

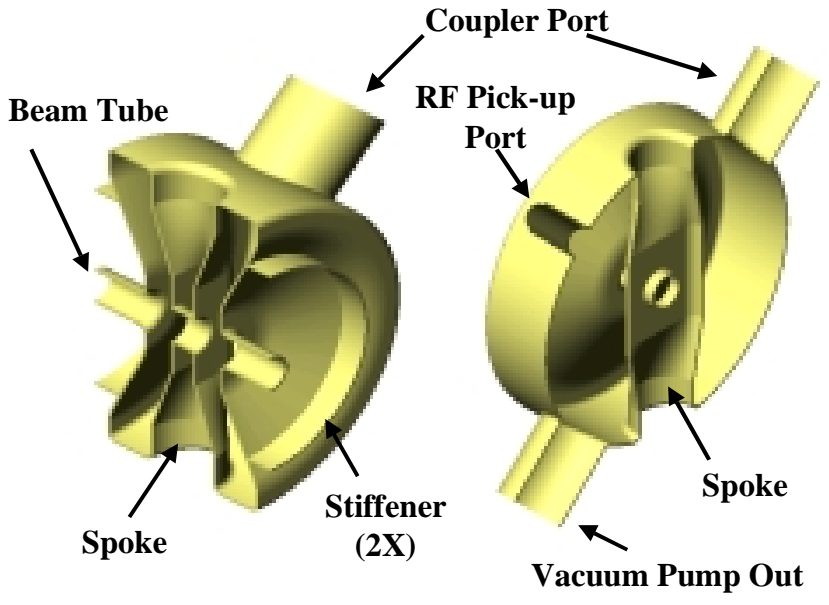

(a)

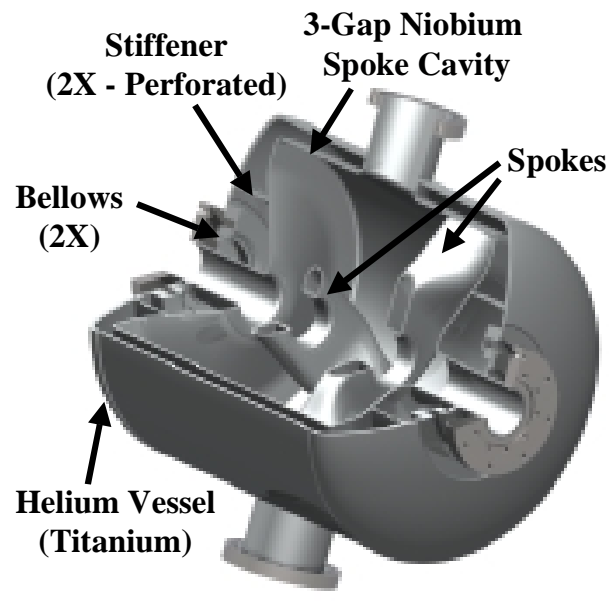

(b)

FIGURE 2. (a) A $\beta=0.175$ two-gap niobium spoke cavity. (b) A $\beta=0.34$ three-gap cavity and helium vessel. 


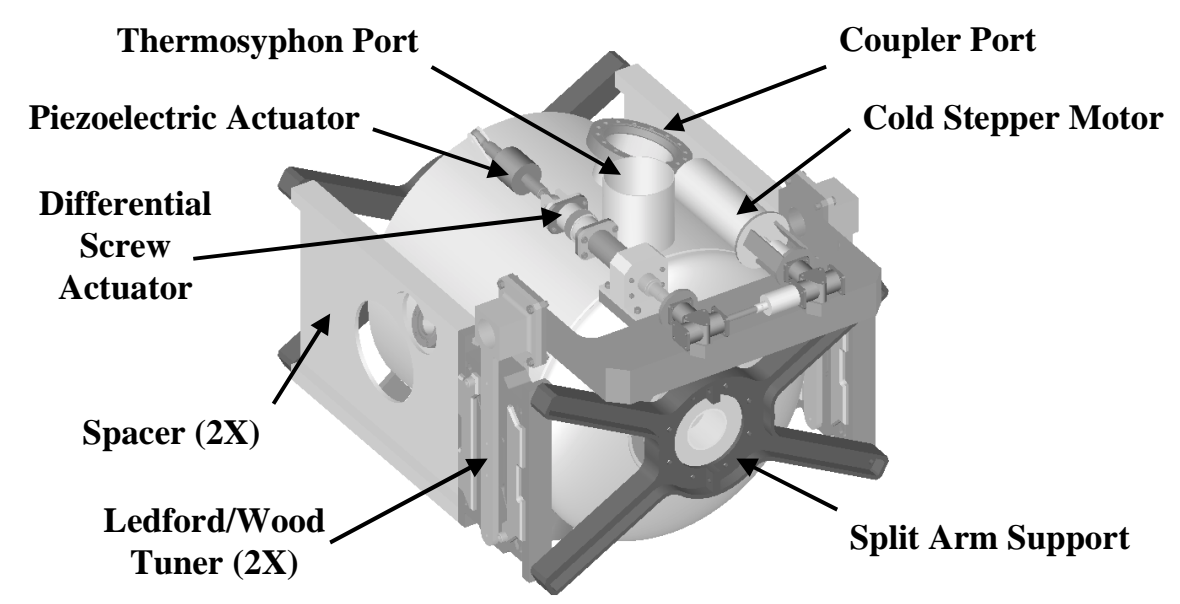

FIGURE 3. The $\beta=0.34$ helium vessel tuner assembly. A cold motor is used to minimize radial penetrations.

modified Ledford/Wood tuner used for the APT program was adopted [5]. The cavity stiffeners are used to transfer the tuning load through the helium vessel back to the cavity where it is balanced by the load on the beam tube. Bellows are used to decouple the beam tubes from the helium vessel, which is similar to the APT design approach. A cold stepper motor drives the tuner (similar to TESLA [6]) though a warm motor with axial drive shaft is possible. A piezoelectric actuator is used to detune the cavity in $<300 \mathrm{msec}$.

The use of individual helium vessels limits the volume available for helium inventory. With its superior cooling properties at $4.5 \mathrm{~K}$, bath cooling of the cavity was selected over supercritical forced flow. Hence, boiling of the helium is anticipated with the potential for vapor locking. To cope with space constraints, provide reasonable helium inventory, reduce vapor locking and improve heat transfer, an open-loop thermosyphon cooling approach was selected. Fig. 4 shows details of the $\beta=0.34$ cryomodule thermosyphon and analytical predictions for mass flow rates and flow quality [7]. The analysis includes bellows in the runs between risers. Orifice plates at the bottom of the risers balance the flows. The reservoir is located in the cryomodule Tee section.

The fixed power coupler is a $75 \Omega$, coaxial, unbiased unit [8]. Couplers are oriented $20^{\circ}$ from vertical, with adjacent couplers in a lattice on alternate sides of the module. The couplers closest to the center Tee section are on the same side of the module. The near vertical orientation was due to APT tunnel constraints. The alternating-sides coupler arrangement is necessary to maintain clearance between large WR2300 waveguides (0.584

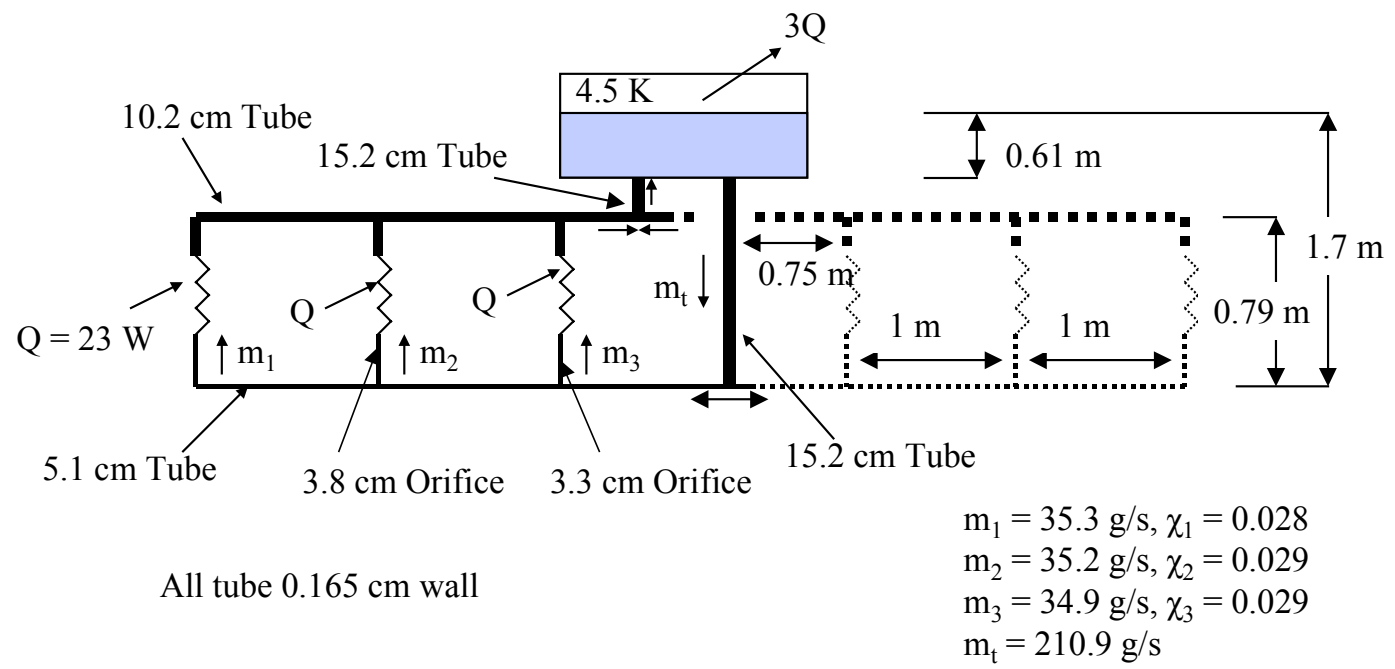

FIGURE 4. Thermosyphon schematic and analytical results for the $\beta=0.34$ cryomodule. Bellows in the runs between risers were included in the analysis but are not shown. 
TABLE 3. Estimated heat loads (Watts) for the $\beta=0.34$ Cryomodule. No margins are assigned.

\begin{tabular}{lcc}
\hline \multicolumn{1}{c}{ Component (Number) } & $\mathbf{4 . 5} \mathbf{~ K}$ & Shield \\
\hline Cavities (6) & 87.8 & 0 \\
Couplers @ 100 mA (6) [9] & 24 & 123.6 \\
Beam Tube (2) & 1.4 & 2.94 \\
Current Lead Pair (2) [11] & 0.8 & 3.2 \\
Magnet/Strongback Supports & 6 & 48 \\
Bayonets (4) Male \& Female & 2.93 & 4.81 \\
Relief Lines (3) & 0.19 & 3.4 \\
Valves (4) & 1 & 10 \\
Cables, Radiation, HOM & 9.22 & 27.84 \\
Total & $\mathbf{1 3 3 . 3}$ & $\mathbf{2 2 3 . 8}$ \\
\hline
\end{tabular}

X $0.146 \mathrm{~m}$.). Heat loads were calculated [9] for a single-point thermal intercept, using techniques developed for APT [10] (see Table 3). The coupler is also the only heliumvessel-assembly support structure, simplifying assembly with fewer penetrations through shields and blankets. Fewer penetrations through the magnetic shields reduce magneticfringe fields. Figs. 5 (a) and 5 (b) are sections of the coupler and cryomodule, respectively.

While the helium vessel is titanium, due to the short length of the vessel, the center support by the coupler, and the bellows on each end of the vessel, it may be reasonable to consider a stainless steel vessel for this application. This is under review.

The solenoids are mounted on compression posts similar to those described in [12]. To minimize complexity, a low, 20-A operating current was selected. The subsequent inductance resulted in a long charge time. Use of a persistent mode switch is being considered. This would permit higher current while reducing lead joule heating, resulting in lower inductance and shorter ramp times.

Fig. 6 is the $\beta=0.34$ cryomodule flow schematic. Supercritical helium at $4.6 \mathrm{~K}$ and 4 atm is supplied to the module. The flow is split with a portion expanded by a JT valve to fill the thermosyphon reservoir. The remaining flow is recooled and directed serially to the solenoids. A recooler between solenoids is sized so that the downstream magnet is not

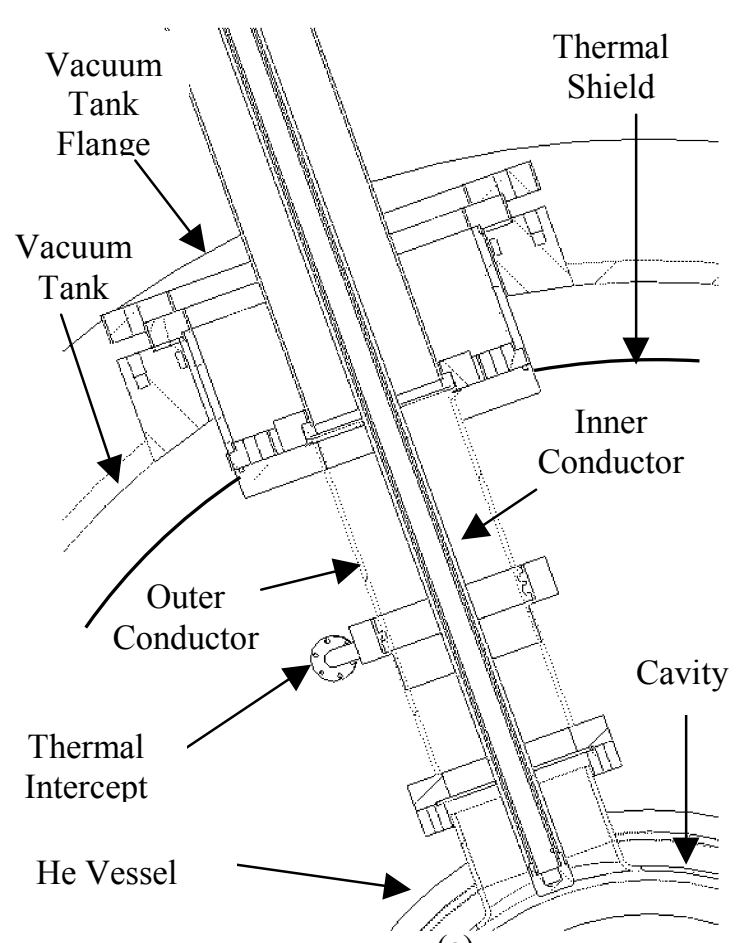

(a)

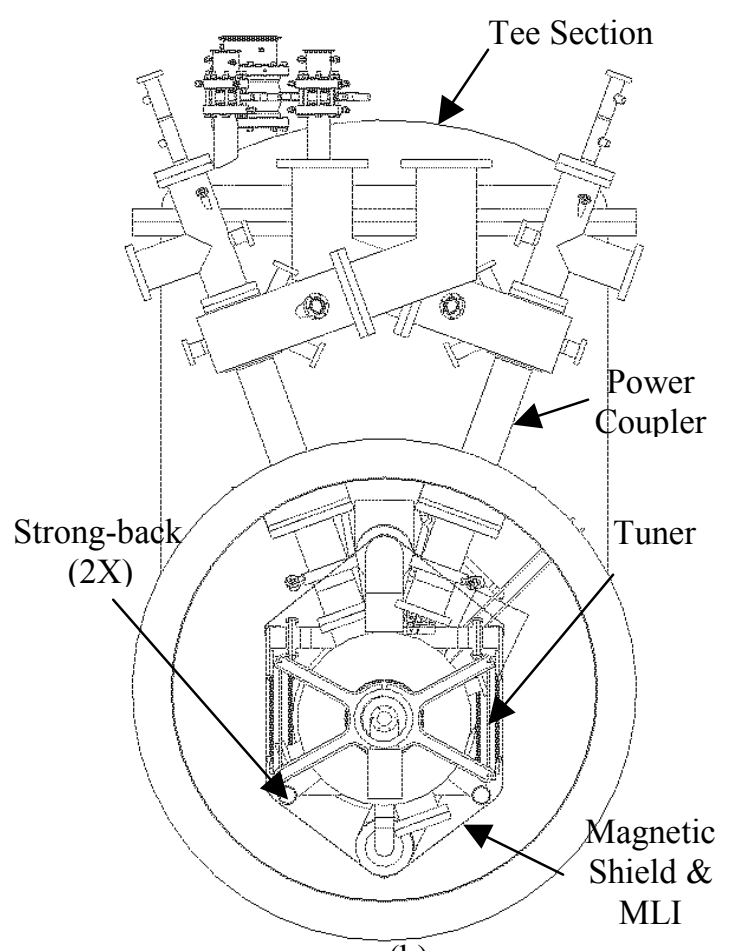

(b)

FIGURE 5. (a) Coupler - vacuum vessel interface. (b) Cryomodule section. Thermal shield not shown. 


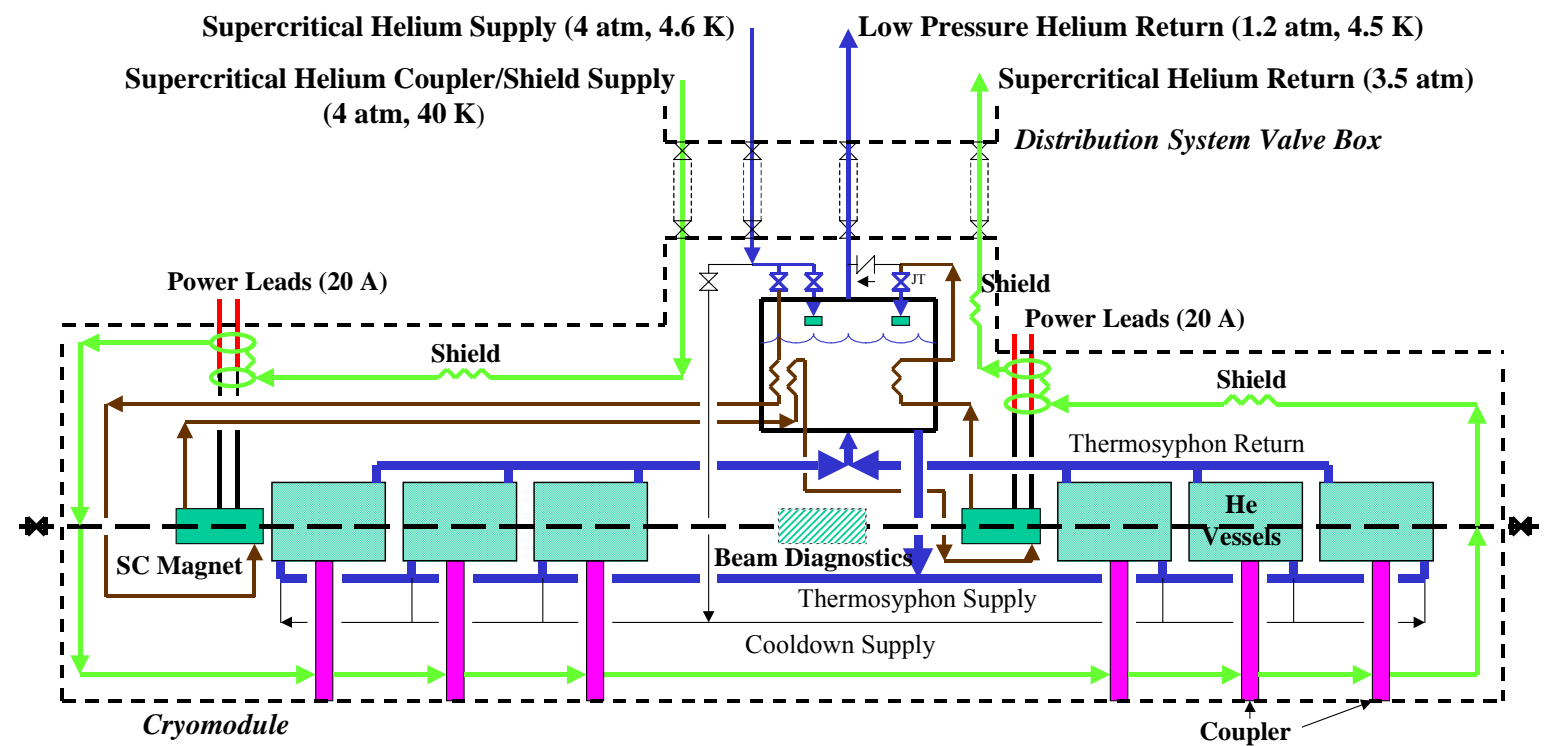

FIGURE 6. Flow schematic for the $\beta=0.34$ cryomodule.

impacted by an upstream magnet quench. A recooler after the downstream magnet removes quench or other heat from the flow. The supercritical flow is then throttled to the thermosyphon reservoir pressure to produce liquid and allow the return of useful cold gas to the cryoplant. This feature eliminates the need for a separate distribution-system return line.

The shields and intercepts are cooled by a flow of supercritical helium at 4 atm and 40 $<\mathrm{T}<55 \mathrm{~K}$. Current leads are conductively cooled with a $40 \mathrm{~K}$ intercept.

\section{CRYOMODULE ASSEMBLY}

Initial cryomodule assembly will be performed in a cleanroom. The cavity vendor provides the mated cavity and helium vessel. After chemistry, high pressure rinsing, and testing, a coupler is mated to the cavity coupler port to form the helium vessel assembly. At this point, the relative positions of beam centerline, the coupler inner flange and assembly mounting pads are known. The assembly is mounted on a pre-aligned strongback (Fig. 7) and fiducials are added to outer coupler flanges for relating its position to that of the beam tube centerline. Beam tubes are then installed and the assembly is temporarily locked-down to the strong-back. The solenoid magnet assemblies are similarly mounted on

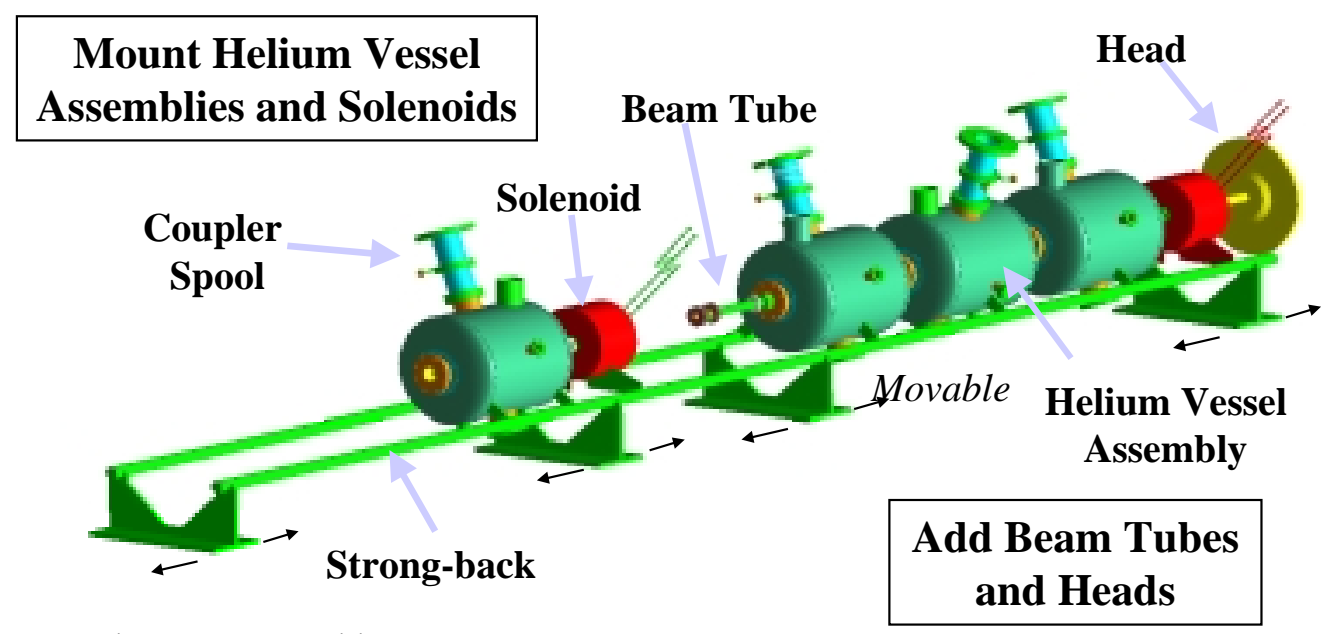

FIGURE 7. Cleanroom assembly. 


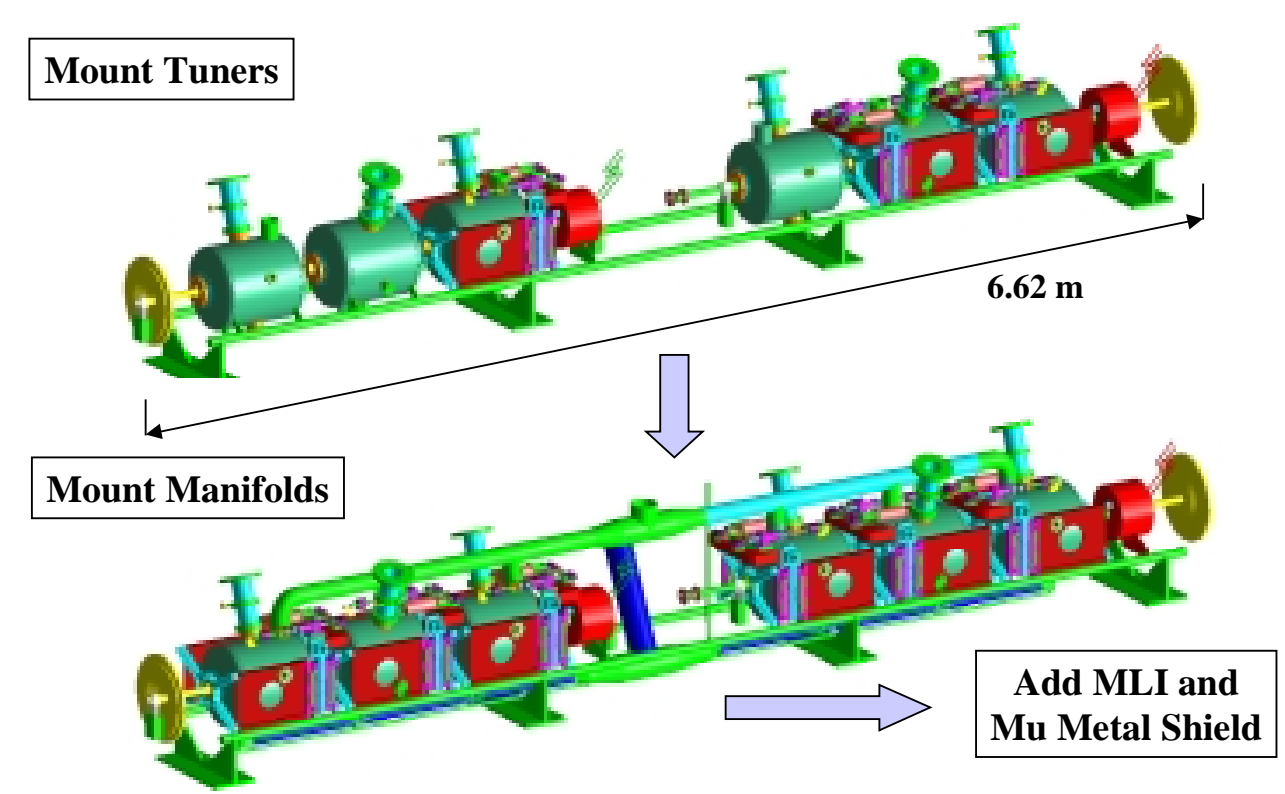

FIGURE 8. Completion of the cold mass assembly.

the strong-back and the beam tubes are installed (cavity to solenoid, solenoid to ambient). Once all the assemblies are mounted, the alignment data is transferred to the fiducials on the outer coupler flanges and final lockdown to the strong-back occurs. All ports are sealed and the remainder of cryomodule assembly is performed outside the clean room.

Once outside the cleanroom, the tuner assemblies are mounted to the helium vessel assemblies (Fig. 8). The thermosyphon and cooldown supply manifolds are welded to the appropriate ports. A 15-layer multi-layer insulation (MLI) blanket and a formed Mu metal shield (1 mm thick) are placed around the manifolds, completing the cold mass assembly.

The cold mass assembly is inserted into the run of a prefabricated Tee section [13]. This section consists of a Tee-shaped vacuum shell with a copper thermal shield, a $1 \mathrm{~mm}$ thick room-temperature magnetic shield, and MLI blankets (4@15 layers ea.) preinstalled (similar to CEBAF [14]). Once inserted, vacuum tanks with preinstalled thermal shields, MLI blankets, and magnetic shields, are mated to the Tee section (Fig. 9). Bridging of shields and MLI blankets between Tee and vacuum cylinders is then completed.

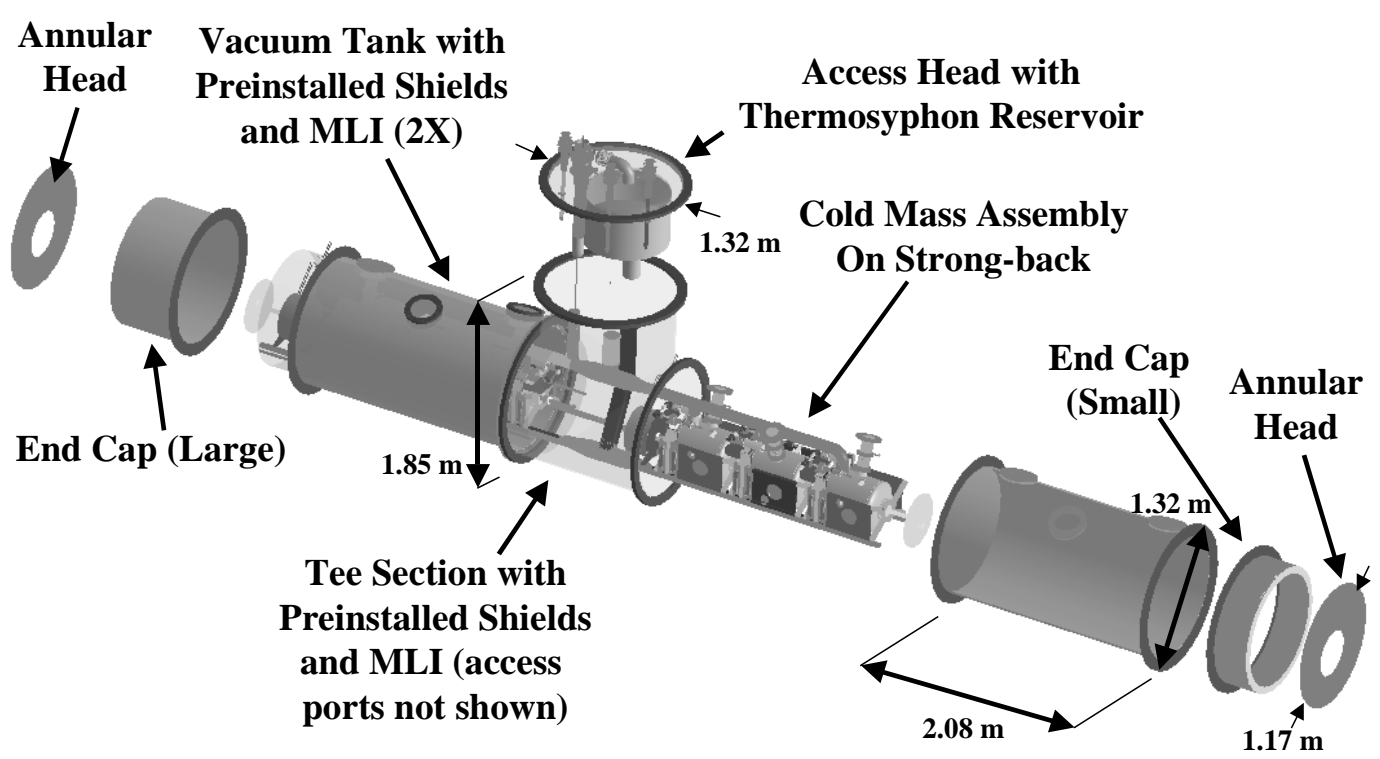

FIGURE 9. Final cryomodule assembly. Thermal, magnetic and MLI shields not shown. 
The helium vessel assemblies and solenoids are attached to the vacuum cylinders and aligned. The assemblies are unlocked from the strong-back and the strong-back is removed. Current feedthroughs are made-up and the Tee-section head assembly is installed in the Tee's branch. Pipe connections are made through ports in the side of the Tee. Finally, after installing the appropriate end shields, the vacuum end caps and annular heads are mounted.

\section{SUMMARY}

A cryomodule concept for the ADTF LEL spoke cavities has been described. A number of concepts and components from previous programs have been adopted. Assembly is simple and cleanroom time is minimized by axial insertion of the cold mass assemblies into the vacuum vessels. Use of the coupler as the sole helium-vessel-assembly support structure minimizes the potential for thermal shorts and magnetic fringe fields, and reduces the overall part count. Thermosyphon flow has been adopted to cool the cavities, which reduces potential vapor locking and improves heat transfer. This concept can easily be extended to the lower- $\beta$ units. Since completion of this work, the constraint of fitting the cryomodule into the APT tunnel has been relieved and coupler position will be revisited.

\section{ACKNOWLEDGEMENTS}

This work is supported by the U.S. Department of Energy through funding source \#NE-AF-5700000.

\section{REFERENCES}

1. Shepard, K.W., Kedzie, M., Delayen, J.R., Pillar, C., Porcellato, A.M., "Development of Niobium Spoke Cavities for a Superconducting Light-Ion Linac,” LINAC ‘98, Chicago, IL, August 23-28, 1998.

2. Garnett, R.W., Wangler, T.P., Krawczyk, F.L., and Kelley, J.P., "Conceptual Design of a Low- $\beta$ SC Proton Linac," Proceedings of the 2001 Particle Accelerator Conference, Chicago, Il, June 18-22, 2001.

3. Krawczyk, F.L., et al., "Design of a Low- $\beta$, 2-Gap Spoke Resonator for the AAA Project," Proceedings of the 2001 Particle Accelerator Conference, Chicago, IL, June 18-22, 2001.

4. Krawczyk, F.L., et al., "Status of the LANL Activities in the Field of RF Superconductivity," Proceedings of the $9^{\text {th }}$ Workshop on RF Superconductivity, La Fonda Hotel, Santa Fe, NM, Nov. 1999.

5. Campbell, B.M., Kelley, J.P., Valicenti, R.A., Waynert, J.A., Fagan, M.J., Puckett, A.D., Engineering Design of the APT Cryomodule, LINAC'98, Chicago, IL, August 23-28, 1998.

6. Weisend, J.G, et al., "Operating Experience with the First TESLA Test Facility Cryomodule," Proceedings of ICEC17, Bournemouth, UK, July 1998.

7. Kelley, J.P., Open-Loop Thermosyphon Flow in the ADTF $\beta=0.34$ Spoke Cavity Cryomodule, LANSCE1:01-017 TN-Rev. 1, LA-CP-01-248, Los Alamos National Laboratory, April 16, 2001.

8. Schmierer, E., ADTF Spoke Cavity Input Power Coupler Design Concept, ESA-DE: 01-065, Los Alamos National Laboratory, May 17, 2001.

9. Waynert, J.A., Thermal Analysis on ADTF Spoke Cavity Power Coupler, ESA-EPE:01-075, LA-UR \#013687, Los Alamos National Laboratory, March 30, 2001.

10. Waynert, J.A. and Prenger, F. C., "A Thermal Analysis and Optimization of the APT $210 \mathrm{~kW}$ Power Coupler," LINAC'98, Chicago, IL, August 23-28, 1998.

11. Daney, D.E., Dillard, J.E., and Forsha, M.D., "Cryogenic Equipment," in Handbook of Cryogenic Engineering, J.G. Weisend II, ed., Taylor \& Francis, Philadelphia, 1998, pg. 405.

12. Hiller, M.W., Lieb, B.W., Weber, E.M., Waynert, J.A., and Pfund, P.A., "SSC Quadrupole Magnet Cryostat Design Alternative," Adv. Cryo. Eng., Vol. 37, R.W. Fast, ed., Plenum Press, NY (1992).

13. LaFave, R., Kelley, J.P., and Roybal, P., ADTF Spoke Resonator Cryomodule Alignment Procedure, LANSCE-1:01-78 TM, Los Alamos National Laboratory, June 15, 2001.

14. Schneider, W., et al., "Thermal Performance of the CEBAF Superconducting LINAC Cryomodule," Adv. Cryo. Eng., Vol. 39, P. Kittel, ed. Plenum Press, NY 1994. 